\title{
Phytochemical Constituents and Hypoglycemic Effect of Aqueous and Ethanolic Extracts of Murraya Koenigii in Alloxan-Induced Diabetic Rats
}

\author{
Abubakar, N. A. Oise, A.E. and Saidu, A. N. \\ Federal University of Technology, Department of Biochemistry, Minna, Nigeria
}

\begin{abstract}
Phytochemical constituents and the hypoglycemic activity of aqueous and ethanolic extracts of Murraya koenigii (curry leaf) was investigated in alloxan induced diabetic rats. Qualitative phytochemical screening of the aqueous and ethanolic extracts confirmed the presence of alkaloids, Cardiac glycosides, flavonoids, tannins, phenols, phlobotanins, terpenes and emodols in both extracts. Aqueous and ethanolic extracts of Murraya koeniqii administered orally at a dose level of $400 \mathrm{mg} / \mathrm{kg}$ body weight for four weeks showed a significant decrease $(p<0.05)$ in the blood glucose levels of the alloxan induced treated rats when compared with the induced non treated rats. There was no significant difference $(p>0.05)$ in the hypoglycemic activity and weight of the animals treated with aqueous and ethanolic extracts of Murraya koeniqii when compared with animals in the control group (metformin). However, a significant decrease $(p<0.05)$ in weight (g) for the untreated rats was observed. The ethanolic extract showed a better hypoglycemic activity, but the statistical analysis shows no difference. This study reveals the antidiabetic potentials of Murraya Koenigii extracts. Thus, its extract can be further processed for drug development.
\end{abstract}

Keywords: Hypoglycemic, alloxan, phytochemical screening, Murraya koenigii.

\section{Introduction}

Diabetes mellitus is a global disease, found in all nations of the world with high prevalence rate. It is characterized by inability to regulate blood glucose caused by relative or absolute deficiency in insulin. The disease may occur as a result of pancreatic $\beta$-cells impairment, leading to reduction in insulin secretion. It could also occur when the insulin receptors are resistant to the functions of circulating insulin (Ada, 2010). There are two main types of diabetes mellitus depending upon its etiology and treatment. These are type 1 or insulin dependent diabetes mellitus (IDDM) and the type 2 or non-insulin dependent diabetes mellitus (NIDDM). Type 1 diabetes mellitus can only be controlled by insulin therapy (David, et al., 2011). Type 2 diabetes is the most common one and usually starts at later life (over the age of 40) and mainly in obese individuals. In type 2, the insulin producing cells in the pancreas produce inadequate insulin for the body's need. Recurrent or persistent hyperglycemia during diabetes causes glycation of body proteins, which in turn leads to secondary complications affecting eyes, kidneys, nerves and arteries (Sharma, 1993).

The kidney removes the extra sugar from the blood and excretes it through urine to keep the normal level of glucose in the blood. When glucose level exceeds the renal threshold $(160-180 \mathrm{mg} / \mathrm{dL})$ glucosuria occurs with wastage of energy and increased excretion of water and sodium. Different techniques have been employed to reduce the incidence rate of the disease and to cure diabetes; these techniques include drug therapy, dietary therapy and natural product therapy.

Natural products like spices have been recognized to have medicinal properties and possess many beneficial effects on health, such as antioxidant activity, digestive stimulant action, anti-inflammatory, antidiabetic, antimicrobial, hypolipidemic, antimutagenic, hepatoprotective, anti-hypercholesterolemic and anticarcinogenic potential, etc (Lorena, et al., 2002). Murraya koenigii (Rutaceae) is widely used as a spice and condiment in India and other tropical countries. Various parts of Murraya koenigii has been used in traditional medicine for the treatment of rheumatism, traumatic injury and snake bite and it has been reported to have antioxidant, anti-diabetic and anti-dysenteric activities (Keasri, et al., 2007).

The aim of this therapy is to investigate the hypoglycemic activity and phytochemical constituents of Murraya koenigii leaf in ethanolic and aqueous solution. In modern day medicine, four categories of antidiabetic agents are available-Insulin secretagogues, biguanides, thiazolidinediones and alpha glucosidase inhibitors (Arulselvan, et al., 2008). The beneficial effects of these are well documented but not without side effects and also patients develop resistance over a period of time. Insulin therapy affords effective glycemic control, yet its short comings such as ineffectiveness on oral administration, short shelf life, requirement of constant refrigeration and in the event of excess dosage-fatal hypoglycemia limits its usage (Kesari, et al., 2005). Hence, there is a need for evaluation of newer orally active antidiabetic agents. 


\section{Materials And Methods}

Plant Collection / Extract Preparation: Fresh leaves of Murraya koenigii (curry leaf) were collected in April 2013 from a local vegetable farm in Mararaba, Abuja. Nigeria. The leaves were rinsed under running tap and air dried at room temperature with adequate ventilation and pulverized with a blender. The pulverized samples were extracted with ethanol and distilled water by reflux. $100 \mathrm{~g}$ each of the powdered curry leaf was dissolved in $400 \mathrm{ml}$ of ethanol and $600 \mathrm{ml}$ of water and was refluxed for 4 hours at $78^{\circ} \mathrm{C}$ and $100^{\circ} \mathrm{C}$ respectively. The extract was filtered using a muslin cloth. The filtrate was evaporated using a rotary evaporator and concentrated further using a water bath. The extract was collected, weighed and stored in a sterile air tight container and kept in the refrigerator until required for use.

\section{Chemicals} analytical grade.

Alloxan used was obtained from a reputable diagnostic outlet. Ethanol and other reagents used were of

\section{Experimental Animals}

Female adult Swiss Albino rats (100 to $150 \mathrm{~g}$ ) were obtained from the Animal House Centre, Department of Biochemistry, University of Ilorin, Kwara State, Nigeria. They were conveniently housed in the Department of Biochemistry Laboratory II, Federal University of Technology, Minna, under standard environmental conditions (temperature $27 \pm 2^{\circ} \mathrm{C}, 70 \%$ relative humidity, $12 \mathrm{hrs}$ day light/night cycle) and had free access to commercial feed pellets (by growers) and water. The animals were allowed to acclimatize for two weeks before the commencement of research.

\section{Induction of Diabetes}

Prior to diabetic induction, the rats were fasted for 12 hours. A single dose of $400 \mathrm{mg} / \mathrm{kg}$ body weight of freshly prepared solution of alloxan monohydrate was injected intraperitoneally. After 72 hours of induction, blood was collected from tail vein of overnight fasted rats and the blood glucose levels were determined. Animals with blood glucose levels above $150 \mathrm{mg} / \mathrm{dL}$ were selected for the experiments.

\section{Experimental Design}

The animals were in five groups (I, II, III, IV and V) of six rats each for the evaluation of anti-diabetic activity.

Group-I Diabetic rats treated with $400 \mathrm{mg} / \mathrm{kg}$ body weight of ethanolic extract of Murraya koenigii.

Group-II Diabetic rats treated with $400 \mathrm{mg} / \mathrm{kg}$ body weight of aqueous extract of Murraya koenigii.

Group- III Diabetic rats treated with $0.5 \mathrm{mg} / \mathrm{kg}$ body weight of metformin.

Group- IV Diabetic rats with no treatment.

Group -V Non diabetic control rats.

\section{Determination Of Blood Glucose Level}

Blood glucose levels were determined using one touch basic Glucometer. The tail vein of the animals were punctured to access the blood on the glucose strip and subsequent determination of blood glucose on the Glucometer.

\section{Phytochemical Screening}

Phytochemical screening of the extracts was carried out for various plant constituents. The crude extracts were screened for the presence or absence of secondary metabolites such as alkaloids, cardiac glycosides, steroidal compounds, phenolic compounds, flavonoids, saponin, tannins and anthraquinone using standard procedures as described by Trease and Evans 1993, Sofowora 1993.

\section{Statistical Analysis}

All values were expressed as Mean \pm SEM. Statistical analysis was performed by one-way Analysis of Variance (ANOVA) and individual comparisons of the group mean values was done using Duncan test. 
Phytochemical Analysis

\section{Results}

Table.1: Phytochemical Composition of Ethanolic and Aqueous Extract of Murraya koenigii.

\begin{tabular}{|c|c|c|}
\hline Compounds & Ethanol & Aqueous \\
\hline Alkaloids & ++ & ++ \\
\hline Anthranoids & - & - \\
\hline Cardiac glycosides & ++ & ++ \\
\hline Phlobatannins & + & + \\
\hline saponin & + & - \\
\hline Anthraquinone & - & - \\
\hline Steroids & - & - \\
\hline Terpenes & + & + \\
\hline Tannins & + & + \\
\hline Flavonoid & + & + \\
\hline Phenols & + & + \\
\hline Emodols & + & + \\
\hline
\end{tabular}

Keys: - (absent), + (moderately present), ++ (highly present).

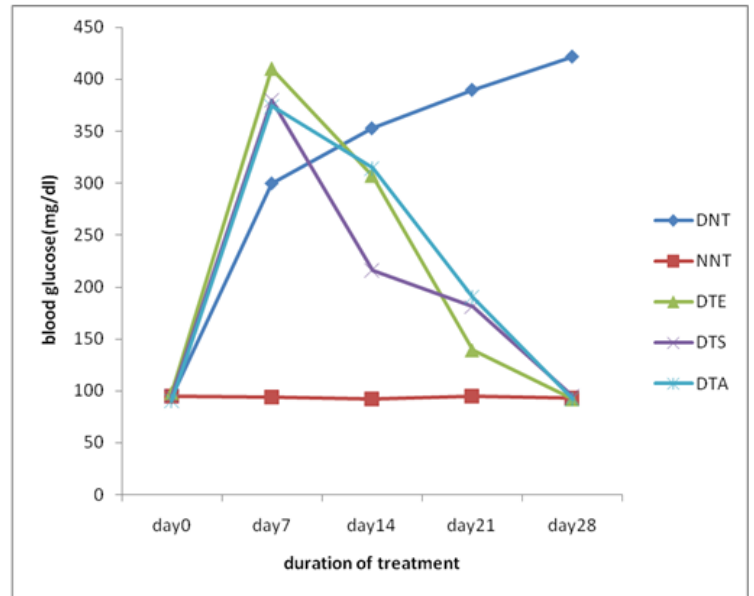
KEY
- DNT-diabetes
not treated
-NNT-not
induced not
treated.
-DTE- diabetes
treated with
ethanol.
-DTS-diabetes
treated with
standard.
-DTA-diabetes
treated with
aqueous.

Figure 1: Blood glucose concentration of diabetic induced untreated rats, non-induced, induced rats treated with Ethanolic and aqueous leaf extract of Murraya koeniqii and induced rats treated with metformin

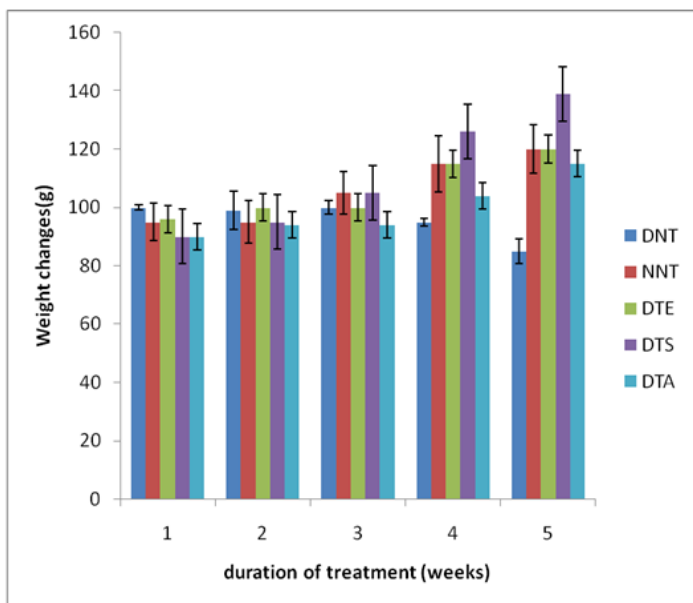

KEY

- DNT-diabetes

not treated

-NNT-not

induced not

treated.

-DTE- diabetes

treated with

ethanol.

-DTS-diabetes

treated with

standard.

-DTA-diabetes

treated with

aqueous.

Figure 2: Variation in the body weight of diabetic induced untreated rats, non induced, induced rats treated with Ethanolic and aqueous leaf extract of Murraya koeniqii and induced rats treated with metformin

\section{Discussion}

Plants are important sources of potentially useful structures for the development of new chemotherapeutic agent (Baskeran, et al; 2011). Phytochemical components are responsible for both pharmacological and toxic activities of plants (Lawal, et al; 2005). Plants are known to produce this compounds to protect themselves against predators but studies showed that they can also be used to protect humans against diseases. This study revealed the presence of various medicinal important phytochemicals in both aqueous and ethanolic extract of Murraya koenigii. (Table 1). 
Alkaloids and cardiac glycosides are highly present in both extracts (aqueous and ethanolic extract of M. koenigii ). Alkaloids are known for their antimicrobial property (Ahmed, et al; 2010) and protection against chronic diseases (Akindele, et al; 2007). Alkaloids are used in the development of powerful painkillers, cocaine, caffeine, nicotine, analgesic morphine, antibacterial barbering and the anti malarial drug quinine are all derivatives of alkaloids (Manske, 1965). Alkaloids also posses anti oxidizing effect thus reduce nitrate regenetration which is useful for protein synthesis, suppress the transfer of sucrose from stomach to small intestine. Cardiac glycosides are used in the development of drug for congestive heart failure drugs like Quabain and dioxin. Phlobotanins, terpenes, tannins, flavonoids, phenols and emodols are moderately present. Tannins have anti bacterial potentials due to their ability to react with protein to form stable water soluble compound thereby killing the microorganism by directly damaging its cell membrane, Phenols are known for their anti hyperglycemic activity ( Nkirote, et al., 2011). Phenols also posses antiviral properties (Lu, et al., 2004 )antibacterial and antiparasitic effect. (Akiyama, et al.,2011). The presence of these phytochemicals correlates with the findings of Baskeran, et al 2011. However, the absence of anthranoids, anthraquinones and steroids in both extracts and the presence of saponins in ethanolic extract but absence in aqueous extract corresponds with the work of Tijjani et al., 2007 that not all phytochemicals are present in all parts of the plant and those present differs with the solvent used in the extraction processes (Tijjani, et al; 2007).

Diabetes mellitus arise from the irreversible destruction of the pancreatic B.-cells causing deregulation and reduction of insulin secretion (Junod et al., 1969). Evaluation of hypoglycemic potentials of anti diabetic agent using alloxan induced hyperglycemia model has been described by Szkudelski, 2001. The reduction in blood glucose level observed in rats treated with aqueous and ethanolic leaf extracts of M. koeniqii is an indication of antidiabetic potentials and also the insignificant differences observed in the extracts treated group when compared with the group treated with the standard drug metformin (figure 1). It also suggests it's hypoglycemic properties which is in agreement with the findings of Yadav et al; 2002. The hypoglycemic effect of this extract may be linked to its phytoconstituents especially flavonoids which act by potentiating the insulin effect either by increasing the pancreatic secretion of insulin by the cells of islet of langerhan or its release from bound insulin in alloxan induced diabetic rats. (Chakkravarthy, et al; 1980).

The insulin deficiency caused drastic elevation in glucose levels as a result of excessive production of endogenous changes in body weight (Ramanchandran, et al; 2011) which may be as a result of excessive breakdown of protein and lipid by insulin deficiency. The improvement of body weight in rats treated with $\mathrm{M}$. koeniqii extracts (figure 2) may be as result of improvement in glucose metabolism. This finding is contrary to the report of Xie, et al; who reported a significant loss of body weight in diabetic rats administered with $80 \mathrm{mg} / \mathrm{kg}$ of M. koeniqii extract for 10 days.

\section{Conclusion}

The presence of these phytochemicals is an indication that if the plant is properly screened, it could yield a drug of pharmaceutical importance. This study also suggests that aqueous and ethanolic leaf extracts of Murraya koeniqii possess some hypoglycemic properties that could be proceesed for drug development.

\section{Aknowledgements}

Our sincere gratitude goes to the management of Federal University of Technology, Minna for providing us with the enabling environment to carry out this work.

\section{References}

[1]. ADA (2010).America Diabetes Association Diabetes care 33, S1 S62 -69.

[2]. Ahmed, E., Nour, B., Mohamed, Y. and Khalid, H.S. (2010). Antiplasmodial activity of some plant. Journal of environmental health research. 4(4)1-6.

[3]. Akindele, A.J., and Adeyemi, O.O. (2007) Anti-inflammatory activity of the aqueous leaf extracts of Byrsocarpus coccineus. Fitoterapia. 78: 25-28.

[4]. Akiyama, H., Fuji, K., Yamasaki, O., and Oono, T. (2001). "Antibacterial action of several tannin against staphlococos aureus. Journal of antimicrobial Chemotherapy. 48 (4):487 - 91

[5]. Arulselvan, P., and Subramanian, S. (2008). Ultra-structural and Biochemical Abnormalities in the Liver of Streptozotocin-Diabetic Rats: protective effects of Murraya Koenigii. Journal of Pharmacological and Toxicological methods 3(3):190-202.

[6]. Baskeran, c., ratha, v., and kanimoz, d. (2011). Phytochemical and antimicrobial analysis of Murraya koenigii. 2(6)1807-1810.

[7]. Chakkravarthy, B.K., Gupta, S., Gambir, S.S. and Gode, K.D. (1980). Pancreatic beta cell regeneration. A novel mechanism of Marsupium Rxb. Indian journal of pharmacology. 12:123-127

[8]. Chatterji, S., Singh, R.K., Shukla, S., Yadav, D.K., and Watal, G. (2010). Glycemic effect of freeze dried Murraya koenigii - an evidence based study. International Journal Pharma and Bio Science. 1(2):1-9

[9]. David, G., and Gardner, D. (2011). Greenspan's basic \& clinical endocrinology (9th edition). New York: McGraw-Hill Medical. pp. Chapter 17.

[10]. Junod, A., Lambert, A.E., Atanffacher, W., and Renold, A.E. (1969). Diabetogenic action of streptozotocin relationship of dose to metabolic response. Journal of Clinical Investigation. 48: 2129-2139. 
[11]. Keasri, A.N., Kesari, S., Singh, S.K., Gupta, R.K., and Watal G. (2007). Studies on the glycemic and lipidemic effect of Murraya koenigii in experimental animals. Journal of Ethnopharmacology. 112: 305-311

[12]. Kesari, A.N., Gupta, R.K., and Watal, G. (2005). Hypoglycemic effects of Murraya koenigii on normal and alloxan-diabetic rabbits. Journal of Ethnopharmacology. 97(2):247-251.

[13]. Lawal, M., Wasagu, R.S.U. and Ladan, M.J. (2005). Hepatotoxicity risk assessment of neem (Azadirachta indica) seed extract using albino rats. Biological and Environmental Sciences Journal for the Tropics 2(2):36-38.

[14]. Lorena ,P., Renzo, B.,Stefania, U., and Lafranco, S. (2002). Antioxidant activity of sage(Salvia Officinalis and fruticosa) and Oregano (Origanum Onites and $\mathrm{O}$ indercidens) extract to the phenolic compound content. Journal of the science of food and agriculture.82:1645-1651.

[15]. Lu, L., Lius, S., Jiang, S. and Wu, S. (2004). Tannin inhibits HIV entry by targeting 9 p41 Acta pharmacologica sinica 25 (2): 213 8.

[16]. Manske, R. H. (1965). The Alkaloids. Chemistry and Physiology. Volume VIII, New York. Academic Press, p. 673.

[17]. Nkirote, C.K., Kathenya, I.J., Michael, O., Clare, M., Konrad, B.H., and Vellingiri, V. (2011). Antioxidant and Antidiabetic Properties of Condensed Tannins in Acetonic Extract of Selected Raw and Processed Indigenous Food Ingredients from Kenya. Journal of Food Science. 76(4): 560-567.

[18]. Ramachandran, R., Zhao, X.F., and Goldman, D. (2011). Proceedings of the national academy science U.S.A. 108(38);1585815863.

[19]. Sharma, A. K. (1993). Diabetes mellitus and its complications: an update. New Delhi:Macmillan India Ltd, (pp 92-205).

[20]. Sofowora, A.E. (1993). Medicinal Plants and Traditional Medicines in Africa. $2^{\text {nd }}$ edition, Spectrum Books, Ibadan, Nigeria, p.289, Szkudelski, T. (2001). The mechanism of Alloxan and Streptozocin action in $\beta$-cell of the rats' pancreas. Physiological Research. 50: 536-546.

[21]. Tijjani, I.M., Bello, I., Aliyu, A., olunnshe, T. and Logun, Z. (2007). phytochemical and antibactenanl study of root extract coch lospermum tinctoricm. American research journal of medicinal plant 3:16 - 22 .

[22]. Trease, G.E., and Evans, W.C.A. (1983). Textbook of Pharmacognosy, 12th edition. Bailere Tindall, London. p.241.

[23]. Xie, J. T., Chang, W. T., Wang, C. Z., Mehendale, S. R., Li, J., Ambihaipahar, R., Yadav, S.V., Vats, V., Dhunnoo, Y., and Grover, J.K. (2002). Hypoglycemic and untihyperglycemic activities of Muraya koenigii leaves in diabetic rats Journal ethno pharmacology 82:1111-1119.

[24]. Yadav, S.V., Vats, V., Dhunnoo, Y., and Grover, J.K. (2002). Hypoglycemic and antihyperglycemic activities of Murraya koenigii leaves in diabetic rats Journal of ethno pharmacology. 82:1111-1119.

[25]. Yakubu, M.T., Adesokan, A.A. and Akanji, M.A. (2006). Biochemical change in the liver kidney and serum of rat following chronic administration of cimetidine. African Journal of biomedical research 9:213-218. 